\title{
Cooperação judicial em matéria criminal no mercosul: reconhecimento mútuo e modelo horizontal de cooperação
}

\author{
Judicial cooperation in criminal matters in mercosur: \\ mutual recognition and horizontal model of cooperation
}

\author{
NEREU JOSÉ GIACOMOLLI* \\ nereu@giacomolli.com \\ CAÍQUE RIBEIRO GALÍCIA** \\ caique.ribeiro@ufms.br
}

GALILEU - REVISTA DE DIREITO E ECONOMIA - e-ISSN 2184-1845

Volume XXI $\cdot 1^{\text {st }}$ July Julho $-31^{\text {st }}$ December Dezembro $2020 \cdot$ pp. 77-94

DOI: https://doi.org/10.26619/2184-1845.XXI.2.5

Submitted on October $30^{\text {th }}, 2020$. Accepted on November $10^{\text {th }}, 2020$

Submetido em Outubro, 2020. Aceite a 10 de Novembro, 2020

RESUMO: A carência de normatividade consistente e uniforme acerca da cooperação judicial internacional em matéria criminal, no Brasil, produz uma série de problemas, mormente em face das reservas constitucionais e legais. Tal situação pode diminuir o âmbito de proteção dos direitos fundamentais e dificultar a solidariedade internacional na prestação da tutela jurisdicional efetiva. $\mathrm{O}$ artigo problematiza o reconhecimento mútuo no âmbito do MERCOSUL, cuja integração regional não evoluiu como a existente no espaço europeu. A harmonização legislativa é um fator de efetivação do reconhecimento mútuo e aprimoramento dos mecanismos de cooperação judicial internacional. Para os países do MERCOSUL já está consolidado um padrão mínimo de respeito a direitos fundamentais tendo como parâmetro o sistema interamericano de proteção (Convenção, Comissão e Corte), o qual deverá ser implementado e aplicado. A perspectiva de descentralização

\footnotetext{
* Doutor pela Universidad Complutense de Madrid. Professor do Mestrado e Doutorado em Ciências Criminais da Pontifícia Universidade Católica do Rio Grande do Sul (PUCRS). Professor convidado no Mestrado em Direito da Universidade Autónoma de Lisboa/IURJ. Investigador do Ratio Legis, da UAL/Lisboa: Corpus Delicti - Estudos de Criminalidade Organizada Transnacional. Orcid: 0000-0003-1753-0334. Lattes: http://lattes.cnpq. br/5969235847033808.

** Doutorado e mestrado em Ciências Criminais pela PUCRS com estágio de pesquisa sanduíche na Universitá degli studi di Bologna. Estágio Pós-doutoral em andamento em Antropologia Social (PPGAS/UFMS). Professor adjunto da UFMS. Professor Titular da FACSUL.
} 
Cooperação judicial em matéria criminal no mercosul: reconhecimento mútuo e modelo horizontal de cooperação NEREU JOSÉ GIACOMOLLI, CAÍQUE RIBEIRO GALÍCIA

GALILEU · e-ISSN 2184-1845 - Volume XXI - Issue Fascículo 2 - 1st July Julho - 31

e horizontalidade na cooperação judicial internacional possibilita um equilíbrio entre a persecutio criminis e a proteção dos direitos fundamentais.

PALAVRAS-CHAVE: Cooperação judicial internacional. Matéria Criminal. MERCOSUL. Reconhecimento mútuo.

ABSTRACT: The absence of consistent and uniform norms on international judicial cooperation in criminal issues in Brazil leads to a series of problems, especially in the face of constitutional and legal reservations. This situation can reduce the scope of protection of fundamental rights and hinder international solidarity in the execution of effective judicial protection. This paper will discuss mutual recognition within MERCOSUL, whose regional integration has not evolved in the same way as the European area. Legislative harmonization is a factor for the effectiveness of reciprocal recognition and the improvement of international judicial cooperation mechanisms. For MERCOSUL countries, a minimum standard of fundamental rights respect has already been consolidated, with the Inter-American system of protection (Convention, Commission, and Court) as a parameter, which should be implemented and applied. The perspective of decentralization and horizontality in international judicial cooperation allows for a balance between the persecution criminis and the protection of fundamental rights.

KEYWORDS: International judicial cooperation. Criminal Matters. MERCOSUL. Mutual Recognition.

\section{CONSIDERAÇÕES INICIAIS}

Ao abordar-se o tema da cooperação judicial internacional, independentemente de sua delimitação temática, temporal e espacial, indispensável refletir acerca dos fenômenos da globalização, do incremento da migração, das novas tecnologias que aumentam a velocidade das comunicações entre pessoas e Estados, da importância dos tratados internacionais, bem como dos binômios soberania nacional e solidariedade internacional, repressão da criminalidade e preservação dos direitos fundamentais. Não se trata de simples comitas gentium, mas de uma obrigação jurídica, havendo uma obrigação jurídica de cooperar com os demais Estados, de modo a afirmar a soberania, com o reconhecimento do Estado de Direito e não de abdicação da soberania doméstica.

O Brasil, como os demais países do MERCOSUL, insere-se no contexto internacional da globalização, o qual aumenta a circulação de pessoas, de bens e serviços, com interações imediatas e simultâneas. Tal fenômeno atinge a esfera criminal, na medida em que a 
criminalidade passou a atuar em redes, produzindo efeitos em diversos países e, muitas vezes, de forma concomitante. Por isso, a investigação do delito, o processo e o julgamento de crimes passaram a necessitar da cooperação de outros países, tanto na perspectiva da produção de diversos meios de prova, quanto na execução de decisões. Mesmo a prática de ilícitos não mais se restringe aos limites territoriais de determinado país e a determinada pessoa, mas envolve uma organização empresarial com intercâmbio internacional dinâmico, sem fronteiras e com redes protetivas de interação e comunicação.

O fenômeno da transnacionalização do crime exige, cada vez mais, o auxílio de outros países. A cooperação na investigação e na incidência da potestade punitiva se insere na solidariedade internacional e na afirmação e preservação da soberania estatal da autoridade requerente da cooperação jurídica, na medida da existência de interesse na preservação do Estado de Direito, de sua ordem jurídica e de sua justiça. A tutela jurisdicional efetiva, em matéria criminal, somente ocorre no processo e pelo processo penal, conduzido por um órgão oficial, com exclusividade em aplicar a pena. Essas especificidades atribuem à cooperação judicial internacional em matéria criminal características próprias em relação ao âmbito civil ou privado.

Os três princípios básicos a serem seguidos na cooperação judicial internacional são a verificação de possível conflito entre o tratado internacional e a lei interna do país, incluída a ordem constitucional (discussão da hierarquia entre tratados e a ordem constitucional e infraconstitucional interna); o dever de reciprocidade (tratamento isonômico) e a aplicação do pacta sunt servanda (cumprimento obrigatório do acordado). Esses princípios recebem uma interpretação conforme a ordem interna e, no caso da cooperação judicial internacional em matéria criminal, a importantes reservas constitucionais (reserva legal, reserva jurisdicional, v.g.).

A transnacionalidade do crime exige um consistente arcabouço legislativo e instituições fortes, com blocos regionais e internacionais, na perspectiva de harmonização e solidez da cooperação judicial internacional. O amplo debate e os inúmeros problemas afetos à cooperação judicial internacional, o presente artigo delimita a temática ao MERCOSUL, mormente na incipiente e deficiente integração regional e no reconhecimento mútuo, como mecanismo integrador. Para tanto, em um primeiro momento serão traçadas algumas reflexões acerca do reconhecimento mútuo na problemática da integração regional do MERCOSUL. Nesse apartado, merece comparação, ainda que limitada, os pontos de distanciamento que há do MERCOSUL com a integração no espaço europeu, bem como os aspectos que se identificam.

Num segundo momento, o artigo enfrenta a harmonização legislativa como justificativa à cooperação internacional. No Case MERCOSUL, desde o Tratado de Assunção (1991) 
existe um compromisso dos países em harmonizar suas legislações para fortalecer o processo de integração (art. 1. ${ }^{\circ}$, TA). Por último, o artigo borda o modelo horizontal de cooperação judicial internacional em matéria criminal, no MERCOSUL.

\section{Reflexões sobre o reconhecimento mútuo no contexto do MERCOSUL: a problemática integração regional}

Reconhecendo-se que a cooperação jurídica internacional em matéria criminal assume diversos significados ao longo do tempo, o estabelecimento de laços institucionais voltados à persecutio criminis é uma demanda alinhada à contemporaneidade do fenômeno da criminalidade transnacional. Muitos desafios se apresentam, na medida em que a cooperação internacional envolve uma gama normativa e institucional, muitas vezes assimétricas e diferenciadas, de tal modo a dificultar a efetiva produção de elementos à persecução penal.

Nesse cenário, o espaço europeu se constitui em um modelo de interação internacional a indicar tendências, as quais podem servir de norte aos demais blocos de países. A criação do espaço comum europeu é uma importante mudança à consolidação da ideia de que "o conceito de espaço não exclui o conceito de território nacional, mas acrescenta a ideia de que os territórios que compõem a União constituem uma unidade geográfica comum”. Isso porque, o espaço comum fomenta também o compartilhamento do dever de garantir a segurança dos cidadãos, além de fundamentalmente instigar ressignificações em relação ao princípio da territorialidade em matéria penal e processual penal.

Isso significa o compartilhamento, na contemporaneidade, tanto dos riscos quanto das soluções dos problemas. Assim se infere na acepção de Daniel Bell, quando afirma: "a nação se torna não só pequena demais para resolver os grandes problemas ${ }^{2}$, como também grande demais para resolver os pequenos"3. De forma mais abrangente, Beck afirma que "a ideia de que em época de riscos globalizados seria possível agir segundo o lema 'conseguimos resolver o problema sozinhos' revela-se uma ilusão fatal"4. Afinal, não é simples,

1 No original, em WEYEMBERGH, Anne - «La cooperazione giudiziaria e di polizia». In: KOSTORIS, Roberto E. Manuale di procedura penale europea. Milano: Giuffrè Editore, 2017, p. 204: “... così il concetto di Spazio non abolisce il concetto di territorio nazionale, ma si aggiunge ad esso per chiarire che i territori nazionali che compongono l'Unione costituiscono un'unità geografica comune".

2 Vale expor os inúmeros problemas de ordem interna e externa que o Reino Unido enfrentou durante o processo da sua saída da União Europeia (BREXIT) e as incongruências e incertezas quanto aos reflexos sociais, financeiros e políticos dessa decisão.

3 Em GIDDENS, Anthony - Mundo em descontrole: o que a globalização está fazendo de nós. Rio de Janeiro: Record, 2011, p. 23.

4 Em BECK, Ulrich - A Europa alemã de Maquiavel a Merkievel: estratégias de poder na crise do euro. Lisboa: Edições 70, 2013, p. 33. 
ou sequer possível a distinção clara entre o que é política interna ou externa ${ }^{5}$ daí a importância da cooperação ${ }^{6}$ entre Estados.

No caso do espaço europeu, embora seu processo de integração possa ser associado à Comunidade Europeia do Carvão e do Aço (CECA-1952), é de fato com o Tratado de Lisboa (2007) que se dá uma reorganização estrutural com a distribuição de competências da União europeia e a extinção do método intergovernamental de cooperação para a forma comunitária7. Assim, o Tratado de Lisboa não inova apenas no plano institucional e decisório, mas altera o conteúdo da atividade cooperacional ao consagrar o princípio do reconhecimento mútuo das sentenças e decisões judiciárias, buscando a aproximação da base jurídica legislativa comum, reforçando os poderes do Eurojust e da Europol, bem como lançando os alicerces ao Ministério Público Europeu ${ }^{8}$.

Desta forma, a ideia do espaço de liberdade, segurança e justiça é garantido pela atuação conjunta da harmonização legislativa, do princípio do reconhecimento mútuo e da cooperação operacional ${ }^{9}$. Nessa estrutura há o compartilhamento de competências entre a União e os Estados membros, agora englobando todos os âmbitos do espaço de liberdade, segurança e justiça, permitindo a racionalização e sistematização de cada um desses setores $^{10}$.

Na prática, a estrutura da cooperação internacional no espaço europeu pensada a partir do paradigma do princípio do reconhecimento mútuo resultou em dois mecanismos de cooperação muito importantes. O primeiro deles é o mandado de detenção europeu (european arrest warrant), que pretendia substituir o processo de extradição dentro do espaço

5 Segundo ZAKARIA, Fareed - The post-american world. New York: W. W. Norton \& Company, 2008, p. 31: "num mundo globalizado, quase todos os problemas ultrapassam as fronteiras. Seja o terrorismo, seja a proliferação nuclear, as doenças, a degradação ambiental, as crises econômicas ou a escassez de água, não há questão que possa ser resolvida sem coordenação e cooperação entre muitos países. Contudo, enquanto a economia, a informação e mesmo a cultura se globalizaram, o poder político formal permanece firmemente nas mãos do estado-nação, apesar de o estado-nação se ter tornado menos capaz de resolver estes problemas de forma unilateral. E os estados estão a revelar cada vez menos vontade de se juntarem para resolver problemas comuns. À medida que o número de atores - governamentais e não governamentais - aumenta e o poder e a confiança nestes atores cresce, a probabilidade de acordo e de ação comum diminui. Este é o desafio principal levantado pela ascensão dos demais - evitar que as forças do crescimento global se tornem as forças da desordem e da desintegração globais".

6 Segundo BECK, Ulrich - A europa alemã. De Maquiavél a Merkievel..., p. 50: "muitas coisas poderiam ser mais fáceis se as pessoas, as organizações que defendem determinados interesses e os políticos deixassem cair a ideia antiquada da soberania nacional e compreendessem que a soberania só poderá ser reconquistada a nível europeu - com base na cooperação, no acordo e na negociação".

7 Em WEYEMBERGH, Anne - «La cooperazione giudiziaria e di polizia». In:: KOSTORIS, Roberto E. Manuale di procedura penale ...., p. 212.

8 Em WEYEMBERGH, Anne - «La cooperazione giudiziaria e di polizia». In: KOSTORIS, Roberto E. Manuale di procedura penale ..., p. 215 .

9 Em MOREDA, Nicolás Alonso - Cooperación judicial em matéria penal em la Unión Europea: la "euro-ordem", instrumento privilegiado de cooperación. Pamplona: Thomson Reuters, 2016, p. 48.

10 Em MOREDA, Nicolás Alonso - Cooperación judicial em matéria penal em la Unión Europea..., p. 48-49. 
europeu e simplificar a entrega de pessoas condenadas ${ }^{11}$. O segundo deles é a decisão europeia de investigação (european investigation order) em matéria criminal. Cada um desses mecanismos possui identidades próprias e por si só merecem estudo destacado, mas que foge do objeto pretendido no presente artigo. Contudo, vale assentar que se constituem em mecanismos de cooperação que partem da relação de reconhecimento mútuo entre as autoridades no contexto de integração regional, pois esse é justamente o contraponto e uma das especificidades próprias da realidade do MERCOSUL.

De maneira abrangente, o reconhecimento mútuo produz, juridicamente, dois efeitos principais: (i) cumprimento automático e sem controle de mérito de decisões judiciais decorrentes de um outro país, com (ii) o mínimo possível de hipóteses de denegação do cumprimento de medidas solicitadas. Esses dois efeitos, por si só, já geram na doutrina mais clássica do processo penal um grande receio, posto que desafiam os conceitos de soberania, território e jurisdição $0^{12}$.

Contudo, mesmo que a ideia do reconhecimento mútuo seja aceita como estratégia apta a equilibrar o devido processo penal e a persecução penal da criminalidade transnacional, existem aspectos controversos que merecem enfrentamento mais aprofundado. Dentre eles, a barreira da previsão normativa em comum é o primeiro desafio que se apresenta, já que enfrenta a própria concepção clássica de Estado-nação no que diz respeito à ideia de soberania estatal. Sem dúvida, tratando-se de direito internacional, é inconcebível a imposição de norma internacional ao sistema interno sem a anuência por meio dos mecanismos formais e materiais ${ }^{13}$.

De maneira geral, nos blocos regionais de países, a internalização das normas dependerá, em primeiro lugar, do estágio de integração, influenciando diretamente no método de internalização com as regras específicas de acordo com a realidade de cada sistema jurídico. No caso da União Europeia, pela própria natureza jurídica (direito comunitário) e estrutura de funcionamento com diversas categorias de atos jurídicos (Regulamentos, Diretivas, Decisões, Recomendações e Pareceres) e fontes normativas (Parlamento, Conselho e Comissão), é de extrema relevância a identificação do instrumento normativo adequado. Só assim é possível saber quais os potenciais efeitos ao direito interno e comunitário, além da questão relacionada com a distribuição de competência da União ou dos Estados-membros.

O reconhecimento mútuo foi sendo construído ao longo dos anos junto com a integração regional dos sistemas jurídicos europeus, inicialmente mais abstratos até o presente

11 Em APRILE, Ercole - Diritto Processuale Penale Europeo e Internazionale. Padova: CEDAM, 2007, p. 60.

12 Em VALENTE, Manuel Monteiro Guedes - Do Mandado de Detenção Europeu. Coimbra: Almedina, 2006, p. 22.

13 Em REZEK, Francisco - Direito internacional público. Curso elementar. São Paulo: Saraiva, 2011, p. 102. 
momento com a previsão expressa (art. 67,3, TFUE). Referida norma está contida no capítulo do espaço de liberdade, segurança e justiça. Assim, há uma clara relação entre a construção jurídica desse espaço comum com o reconhecimento mútuo das decisões judiciais em matéria criminal, um dependendo do desenvolvimento do outro.

Assim, possível conflito entre a norma da União e a Constituição interna de cada Estado membro resolve-se a partir de um dos princípios fundantes da União Europeia, segundo o qual há primazia do direito da União em detrimento ao direito interno, conforme ratificado pela Corte de Justiça ${ }^{14}$. Inclusive, tal premissa ficou firmada no julgamento do caso Advocaten voor de Wereld vs. Leden van de Ministerraad (C-303/05, CJ, 03/05/2007) que colocou em debate a Decisão-Quadro 2002/584/JAI (Mandado de Detenção Europeu) no que diz respeito a possibilidade de execução do $\mathrm{MDE}$ quando o fato não for considerado crime no Estado executor.

O Case MERCOSUL se apresenta bastante diferente, já que ainda há primazia da relação intergovernamental, demandando a internalização das normas a cada país do bloco. Ademais, não há um órgão com competência jurisdicional comum. Desta forma, o Protocolo de Assistência Jurídica Mútua em Assuntos Penais, norma regulamentadora da cooperação judicial internacional em âmbito regional, necessitou ser internalizada pelos países signatários, conforme as especificidades de cada país ${ }^{15}$.

A este respeito, os órgãos com competência para produzir normas jurídicas no espaço do MERCOSUL são o Conselho do Mercado Comum (CMC), o Grupo Mercado Comum (GMC) e a Comissão de Comércio do Mercosul (CCM) que utilizam, respectivamente, as "Decisões", as "Resoluções" e as "Diretivas" (art. 41, POP) como fontes jurídicas de caráter obrigatório aos países parte (art. 9, POP), normalmente dependendo da internalização. De maneira geral, a tomada de decisões dos órgãos requer consenso e a presença de todos países-parte, havendo obrigação (art. 38, POP) para que os próprios países tomem as medidas necessárias para cumprir as normas do MERCOSUL ${ }^{16}$.

14 Vid. SPENCER, John R. - «Mutuo Riconoscimento, armonizzazione e tradizionali modelli intergovernativi». In: KOSTORIS, Roberto E. Manuale di procedura penale europea. Milano: Giuffrè Editore, 2017, p. 325.

15 Datas de Aprovação: Argentina (-); Brasil (26/01/2000); Paraguai (23/12/1997); Uruguai (09/08/1999). Datas de Ratificação: Argentina (09/12/1999); Brasil (28/03/2000); Paraguai (20/01/1998); Uruguai (07/07/2000). (Disponível em <http://www.mre.gov.py/tratados/public_web/DetallesTratado. aspx?id=MXsvPjUvqV+T8s+Xsz78Zg==\&em=lc4aLYHVBodF+kNrtEvsmZ96BovjLlzomcrZruYPcn8=> acesso em 28 jan 2021).

16 Dispõe o art. 40, do Protocolo de Ouro Preto: "Com a finalidade de garantir a vigência simultânea nos Estados Partes das normas emanadas dos órgãos do MERCOSUL previstos no artigo 2 deste Protocolo, deverá seguir o seguinte procedimento: i) Uma vez aprovada a norma, os Estados Parte adotarão as medidas necessárias para sua incorporação ao ordenamento jurídico nacional e comunicarão as mesmas à Secretaria Administrativa do Mercosul; ii) Quando todos os Estados Parte tiverem informado a incorporação a seus respectivos ordenamentos jurídicos internos, a Secretaria Administrativa do Mercosul comunicará o feito a cada Estado Parte; iii) As normas entrarão em vigor simultaneamente nos Estados Parte 30 dias depois da data de comunicação efetivada 
Este panorama geral revela que, inobstante apresentarem caminhos e metodologias normativas diferentes, tanto a União Europeia quanto o MERCOSUL possuem um espaço de consenso e decisão para formulação de normas comuns. Embora em cada um dos exemplos seja diferente o mecanismo normativo, o resultado final (elaboração de uma norma com vinculação a todos os membros) independentemente se o processo formal de incorporação se deu mediante ratificação (caso do MERCOSUL), ou direto (algumas hipóteses no caso da União Europeia).

Logo, situando a divergência no plano político-internacional, o tensionamento acaba sendo mitigado, pois o resultado principal é que haja a vinculação da norma aos países e a respectiva vigência em cada um dos ordenamentos jurídicos internos. Independentemente da forma em que é internalizada, a norma internacional ratificada pelo procedimento formal é suficiente para garantir um standard comum de validade/vigência ao conteúdo normativo internacional.

Não se pode olvidar, é claro, o problema que envolve o conflito interno entre a norma internacional ratificada e a previsão normativa interna de cada país. Contudo, esse problema não tem uma solução jurídica exclusiva, mas depende das forças políticas em ação em cada país. De fato, o fortalecimento ou não das normas internacionais de um bloco regional como o caso do MERCOSUL ainda exige esse componente.

\section{A harmonização legislativa como justificativa à cooperação internacional}

Outro ponto controverso ainda dentro do aspecto normativo é a necessidade de harmonização legislativa como condição à efetivação do princípio do reconhecimento mútuo e o consequente aprimoramento dos mecanismos de cooperação internacional jurídica em matéria criminal.

Mais uma vez a problematização se dá porque as premissas jurídicas em que estão assentados o reconhecimento mútuo e a cooperação judicial internacional não são compartilhadas pela maioria dos juristas. Aliás, importante ressaltar que a cooperação judicial internacional em matéria penal e seus desdobramentos compartilham uma zona de intersecção entre o direito internacional, direito criminal e as relações internacionais, de maneira que os institutos jurídicos nem sempre possuem a mesma lógica dogmática clássica (hermética).

A própria noção do princípio da territorialidade em matéria penal não tem mais a mesma aderência prática para solucionar problemas contemporâneos, diante de como se

pela Secretaria Administrativa do MERCOSUL, nos termos anteriormente estabelecidos. Com este objetivo, os Estados Partes, dentro do prazo mencionado, darão publicidade do início da vigência das referidas normas, por intermédio de seus respectivos diários oficiais". 
apresenta a lógica da criminalidade transnacional, especialmente pensando a realidade dos blocos de integração regional. Resultado disso não precisa ser uma unificação, significando a imposição da mesma ordem jurídica, mas verdadeira "harmonização e coordenação da pluralidade" que "faça face à diversidade de sistemas jurídicos e das suas referências de valores ${ }^{17}$.

Mais do que unificar um único instrumento, a contemporaneidade requer espaços de consenso para soluções conjuntas e coordenadas, aí residindo a harmonização $0^{18}$. Acerca da realidade do MERCOSUL, Raul Cervini já alertava acerca das impossibilidades teóricas e práticas do desenvolvimento de um eventual direito penal supranacional comunitário e, descartada, ao menos momentaneamente, toda a possibilidade jurídica, tanto do ponto de vista substantivo quanto adjetivo, de uma regulação penal supranacional comunitária. ${ }^{19}$

Essa posição se dá, principalmente, desde a constatação da (i) ausência de instâncias supranacionais no processo de tomada de decisões de parte dos órgãos do MERCOSUL; (ii) a não previsão de controle de legalidade dos atos editados pelos órgãos do MERCOSUL; (iii) um controle de controvérsias ainda precário; (iv) a ausência de controle parlamentar, claro e objetivo, das tomadas de decisão; e (v) a necessidade de internalização das normas, ou seja, falta de supranacionalidade dos atos normativos; entre outras críticas ${ }^{20}$. Todavia, é importante destacar que muito se avançou nos pontos críticos apontados, nos últimos 20 anos, embora a falta de órgão normativo supranacional e solução de controvérsias pela via judicial, ainda são problemáticos no âmbito regional.

A unificação em um único estatuto penal é, de fato, inviável de ser operado na prática regional da América Latina. Contudo, é certo que a tutela dos bens jurídicos mais relevantes, os quais demandariam a operacionalização da cooperação judicial internacional já é compartilhada por todos os países, embora com alguma variação normativa quanto aos limites do núcleo, sujeitos, preceito secundário, etc.

A principal repercussão nesse aspecto se dá na possivel necessidade de dupla incriminação como um dos requisitos à cooperação internacional. A primeira dificuldade já se estabelece na medida em que definir os limites de um tipo penal incriminador é uma tarefa bastante complexa e, compará-la com outro sistema jurídico resultaria em emprei-

17 Em VALENTE, Manuel Monteiro Guedes - Do Mandado de Detenção ...., p. 27.

18 Em VALENTE, Manuel Monteiro Guedes - Do Mandado de Detenção ..., p. 55, se pode ver que "a harmonização que difere da unificação - ganha relevância por ser a via mais adequada à construção progressiva de uma política criminal europeia, além de que não podemos admitir a concretização do reconhecimento mútuo isoladamente sem que exista a diminuição de divergências das legislações penais(...)".

19 Em CERVINI, Raúl e TAVARES, Juarez - Princípios de cooperação judicial penal internacional no Protocolo do Mercosul. São Paulo: Revista dos Tribunais, 2000, p. 25.

20 Em CERVINI, Raúl e TAVARES, Juarez - Princípios de cooperação judicial penal internacional ..., p. 26-36. 
tada hercúlea. Afinal, quais seriam os parâmetros para definir a equivalência dos tipos penais entre países diferentes? Todavia, vale a constatação de que a construção da ideia da necessidade de dupla incriminação nasce justamente para ser uma ferramenta impeditiva da cooperação, ainda na lógica fundada na noção de soberania estatal como classicamente concebida ${ }^{21}$. De fato, a ideia de dupla incriminação consiste na "exigência de que o fato objeto da cooperação seja qualificado como infração penal na legislação dos Estados cooperantes, bastando a convergência dos elementos essenciais, pouco importando o nomen iuris e a presença de outros elementos"22.

Com isso, privilegia-se a estrutura geral (tutela de um bem jurídico relevante) às características específicas e elementos adjacentes. E essa é a tendência a ser seguida no porvir da cooperação jurídica internacional, considerando a alteração substancial de uma cooperação de modelo requisitório para modelo ordenativo. Isso abarca a concepção de confiança entre os países como um dos sustentáculos da cooperação judicial contemporânea, especialmente pensando o espaço compartilhado de um bloco regional. Assim, a ideia da dupla incriminação, ou a necessidade de normas penais materiais compartilhadas nos mesmos termos, não encontra supedâneo prático. Por outro lado, do ponto de vista da norma processual, a ideia de harmonização ou coordenação pode se dar, alternativamente, por meio da cooperação judicial internacional, estruturada a partir do reconhecimento mútuo. A esse respeito, o espaço de diálogo dentro de blocos regionais de integração é bastante produtivo para se estabelecer novos mecanismos, justamente porque compartilham dificuldades e pretendem elaborar soluções conjuntas.

A harmonização legislativa, de modo geral, é uma aspiração que sempre teve lugar no direito internacional, mas cuja implementação tem se revelado problemática, especialmente no campo criminal, principalmente pela ausência de representatividade democrática $^{23}$. No Case MERCOSUL, desde o Tratado de Assunção (1991) existe um compromisso dos países em harmonizar suas legislações para fortalecer o processo de integração $\left(\operatorname{art.} .^{\circ}, \mathrm{TA}\right)^{24}$.

21 Vid. BONDT, Wendy De - «Double criminality in international cooperation in criminal matters». In: VERMEULEN, G.; BONDT, W.; RYCKMAN, C.(eds.) Rethinking international cooperation in criminal matters in the EU. Antwerpen: Maklu, 2012, p. 109.

22 Em BECHARA, Fábio Ramazzini - Cooperação jurídica internacional em matéria penal. Eficácia da prova produzida no exterior. São Paulo: Saraiva, 2011, p. 154.

23 Referida crítica é apontada por Raúl Cervini há bastante tempo. De fato, o déficit democrático é um fator muito relevante no desenvolvimento da integração no MERCOSUL, já que, embora exista um Parlamento (PARLASUL), não há ainda uma aderência dos cidadãos com o sentimento de pertencimento a esse espaço, além, é claro, da falta de escolha por meio de sufrágio universal.

24 Disponível em <http://www.planalto.gov.br/ccivil_03/decreto/1990-1994/do350.htm> acesso em 28/o1/2021. 
Contudo, harmonização legislativa não significa, necessariamente, que a mesma norma deva existir em todos os países, mas que compartilhem - talvez em níveis diferentes, dependendo da área a que se refere - padrões normativos (standards) estabelecidos em conjunto e em nível internacional para orientar as normas internas. No que diz respeito às normas tributárias, por exemplo, essa aproximação acaba facilitada em razão da cultura e vontade política dentro do bloco de estabelecer padrões nesse âmbito.

Para os países parte do MERCOSUL já está consolidado um padrão mínimo de respeito a direitos fundamentais tendo como parâmetro o sistema interamericano de proteção ${ }^{25}$. A Convenção Americana de Direitos Humanos (Pacto de San José da Costa Rica, 1969) é a norma para tutela de direitos fundamentais, vinculante a todos os países membros do MERCOSUL, apresentando um sistema de jurisdição e interpretação de competência da Comissão Interamericana de Direitos Humanos $(\mathrm{CIDH})^{26}$ e da Corte Interamericana de Direitos Humanos (CorteIDH) ${ }^{27}$. Além disso, vale destacar o compromisso democrático firmado entre os países parte do MERCOSUL e também a Bolívia e o Chile por meio do Protocolo de Ushuaia (1998), ao estabelecer que a "plena vigência das instituições democráticas é condição essencial para o desenvolvimento do processo de integração"28. O referido protocolo é complementado pelo Protocolo de Assunção sobre compromisso com a promoção e proteção dos direitos humanos do MERCOSUL $(2005)^{29}$ e pelo Protocolo de Montevideo $(2011)^{30}$, o qual reforça o compromisso democrático no âmbito do MERCOSUL.

A controvérsia da falta de um regime normativo penal único, no atual estágio de desenvolvimento do MERCOSUL, não se resolve pela criação de um órgão supranacional com competência legislativa, mas pode se dar pela via da coordenação e harmonização de padrões comuns em todos os países parte. O dever de respeito à $\mathrm{CADH}$ é a linha que deve guiar as decisões judiciais em todos os países (controle constitucional e convencional),

25 Normativamente o sistema interamericano de proteção dos direitos humanos é composto: (i) pela Carta da Organização dos Estados Americanos, 1948; (ii) pela Declaração Americana dos Direitos e Deveres do Homem, 1948; (iii) pela Convenção Americana de Direitos Humanos, 1969; e (iv) pelo Protocolo Adicional à Convenção Americana em matéria de Direitos Econômicos, Sociais e Culturais, 1988. Vid., também, em MAZZUOLI, Valerio de Oliveira - Os sistemas regionais de proteção dos direitos humanos. Uma análise comparativa dos sistemas interamericano, europeu e africano. São Paulo: Revista dos Tribunais, 2011, p. 19.

26 Examina as demandas individuais ou coletivas que dizem respeito a violações de direitos humanos constantes na $\mathrm{CADH}$ e que estejam sendo violados em algum Estado que a tenha ratificado.

27 Com competência consultiva e contenciosa, sua atuação está restrita aos Estados que reconhecem sua jurisdição, que é definitiva e inapelável nos termos da $\mathrm{CADH}$ em matéria contenciosa.

28 Disponivel em <http://www.mre.gov.py/tratados/public_web/DetallesTratado.aspx?id=ktUNNjkHcd6x6b SnkufaDA\%3d\%3d\&em=lc4aLYHVBodF+kNrtEvsmZ96BovjLlzomcrZruYPcn8\%3d>acesso em 28/01/ 2021.

29 Disponivel em <http://www.mre.gov.py/tratados/public_web/DetallesTratado.aspx?id=1\%2frUWpYuZNnue7PI seEbYg\%3d\%3d\&em=lc4aLYHVBodF+kNrtEvsmZ96BovjLlzomcrZruYPcn8\%3d > acesso em 28/01/2021.

30 Disponível em <http://www.mre.gov.py/tratados/public_web/DetallesTratado.aspx?id=dxmiRrluWRS5wpKıla x3qw\%3d\%3d\&em=lc4aLYHVBodF+kNrtEvsmZ96BovjLlzomcrZruYPcn8\%3d $>$ acesso em 28/01/2021. 
razão pela qual, os padrões mínimos ali estabelecidos já são exigíveis em todos os países parte. Vale ressaltar que com esse posicionamento quer-se referir que existe já consolidado um mecanismo compartilhado por todos os membros do MERCOSUL de controle de direitos fundamentais. Isso não significa que tal controle não pode/deve ser aprimorado em vários sentidos, mas que é um padrão comum a que todos os países devem observar, sendo possível alternativa a guiar ao estabelecimento do reconhecimento mútuo das decisões judiciais nesse âmbito regional.

\section{O modelo horizontal de cooperação judicial internacional em matéria criminal, no MERCOSUL}

No contexto geral apresentado, vale ainda destacar que a cooperação jurídica internacional classicamente se estabelecia por intermediação das relações diplomáticas entre os países, orientada principalmente pela reciprocidade ${ }^{31}$ e por uma burocracia típica de um momento ainda pautado pela desconfiança entre os Estados, reforçando as respectivas soberanias. A intensificação das interações internacionais e dos mecanismos de cooperação (carta rogatória e extradição, v.g.), fez com que se aprimorasse a máquina burocrática (técnica e jurisdicional) destinada exclusivamente ao processamento dos pedidos passivos e ativos. Essa realidade, marcada por um aumento exponencial de pedidos, especialmente na última década do século XX, implicou na concentração das atividades relacionadas à cooperação em órgãos administrativos, normalmente ligados ao poder executivo (Autoridades Centrais).

Os tratados internacionais passaram a prever a existência de Autoridades Centrais como forma de auxiliar e agilizar o processamento dos pedidos, centralizando em órgãos administrativos, os quais, após receberem os pedidos, os encaminhava às autoridades competentes ao cumprimento da medida (auxílio direto) ${ }^{32}$. De maneira geral, a atribuição das Autoridades Centrais se relaciona com o "recebimento e transmissão dos pedidos de cooperação jurídica, a análise da adequação destas solicitações quanto à legislação estrangeira e ao tratado que a fundamenta"33, constituindo-se em instância de controle adminis-

31 Em RUSSOWSKY, Iris Saraiva - O mandado de detenção na União Européia: um modelo para o Mercosul. Porto Alegre: Verbo Jurídico, 2012, p. 23-24.

32 Cf. SAADI, Ricardo A. e BEZERRA, Camila C. - «A autoridade central no exercício da cooperação jurídica internacional». In: DEPARTAMENTO DE RECUPERAÇÃO DE ATIVOS E COOPERAÇÃO JURÍDICA INTERNACIONAL. Manual de Cooperação jurídica internacional e recuperação de ativos: cooperação em matéria penal. Brasília: Ministério da Justiça, 2012, p. 22. Cf. Também a Convenção de Haia de Comunicação de Atos Processuais (1965).

33 Em SAADI, Ricardo A. e BEZERRA, Camila C. - «A autoridade central no exercício da cooperação jurídica internacional». In: DEPARTAMENTO DE RECUPERAÇÃO DE ATIVOS E COOPERAÇÃO JURÍDICA INTERNACIONAL. Manual de Cooperação jurídica internacional ..., p. 23. 
trativo dos pedidos. Esse é o modelo mais comum e adotado pelo Brasil, embora o órgão destinado a ser Autoridade Central possa variar conforme estabelecido em cada acordo ${ }^{34}$ firmado. Como regra, a função desempenhada pelas Autoridades Centrais procura facilitar o cumprimento dos pedidos, tornando o procedimento mais célere. Ocorre que a mencionada celeridade só faz sentido quando comparada com o trâmite da carta rogatória e da extradição, que são procedimentos muito mais morosos e que já foram as principais formas de cooperação internacional em matéria penal.

Não se ignora o avanço, especialmente na celeridade do processamento dos pedidos que o auxílio direto, por meio das Autoridades Centrais, teve na virada do século XXI. Contudo, permitir com que os sujeitos que estejam diretamente interessados na solicitação e execução das medidas intermedeiem os pedidos proporcionará maior eficácia no cumprimento do objeto do pedido, além de reduzir ao mínimo a intervenção por parte das autoridades do Poder Executivo ${ }^{35}$ (controle político). Essas são as linhas de desenvolvimento da cooperação horizontal, cuja marca principal é a descentralização das tomadas de decisões, dando preponderância à interação entre as autoridades interessadas no cumprimento do pedido e excluindo, ao máximo, hipóteses de controle político/administrativo. Permitir o estabelecimento de cooperação internacional diretamente entre as autoridades interessadas, judiciais ou administrativas (Ministério Público, Polícias, etc.), contando com o auxílio - quando necessário - das Autoridades Centrais, fortificará o processo de celeridade e efetividade na execução das medidas.

Afinal, a simples celeridade sem atingir os objetivos propostos nos pedidos resulta, na verdade, em ineficácia das medidas cooperacionais. Na prática, a descentralização fornece o conteúdo claro do pedido e, por se tratar de órgãos da mesma classe (entre jurisdições, por exemplo), permite que a execução do pedido seja feita de forma mais adequada ${ }^{36}$.

Existem duas razões principais à implementação dessa forma de cooperação descentralizada na contemporaneidade. A primeira é que a descentralização permitirá a exclusão da dimensão política e intergovernamental do escopo da cooperação em matéria criminal. Isso representará o mínimo desvio possível da finalidade contida na proposta de cooperação entre os atores jurídicos, fomentando o estabelecimento de confiança entre os Estados com menos interferência política ${ }^{37}$. Em segundo lugar, o desenvolvimento da cooperação

34 Genericamente conhecidos como MLAT (Mutual Legal Assistance Treaty - Tratado de Assistência Jurídica Mútua). 35 Em MARTINEZ, Rosa Ana Morán - «La cooperación judicial internacional en el siglo XXI». In: MINISTÉRIO PÚBLICO FEDERAL. Temas de cooperação internacional. Brasília: MPF, 2016, p. 112.

36 Em BECHARA, Fábio Ramazzini - Cooperação jurídica internacional em matéria penal..., p. 28.

37 Em BONDT, Wendy, RYCKMAN, Charlotte e VERMEULEN, Gert - «Horizontalisation and decentralisation: Future perspectives on communication and decisión making». In: VERMEULEN, G.; BONDT, W.; RYCKMAN, C.(eds.) Rethinking international cooperation in criminal matters in the EU. Antwerpen: Maklu, 2012, p. 185. 
internacional na forma horizontal/descentralizada tem como vantagem a comunicação direta entre as autoridades envolvidas no pedido, o que proporciona maior rapidez e eficiência no cumprimento do objeto proposto ${ }^{38}$.

Importante ressaltar que a ideia da descentralização e horizontalidade da cooperação não implica na extinção do papel das Autoridades Centrais, mas na restrição no processamento de pedidos de cooperação ao assessoramento e suporte às autoridades executoras. Assim, a estrutura geral da cooperação internacional continua sendo composta pelas Autoridades Centrais, mas com funções limitadas aos aspectos técnicos e não como canais obrigatórios por onde devam tramitar todos os pedidos.

A perspectiva de cooperação horizontal entre as autoridades nacionais, no caso, entre os países parte do MERCOSUL, possui alguns aspectos potencialmente dificultadores que merecem atenção na viabilização das medidas ${ }^{39}$. Esses aspectos podem ser concentrados em (i) dificuldade na identificação da contraparte competente para execução do pedido; (ii) linguagem e tradução dos termos pedidos e respostas; e (iii) entraves técnicos na operacionalização dos pedidos.

Acerca da identificação da contraparte competente, além da possibilidade de contar com a assistência das Autoridades Centrais (como já mencionado), uma possibilidade é a especialização de grupos destinados a lidar com a cooperação e com competência para executar os pedidos. No caso do Brasil, o Tribunal Regional Federal da $4{ }^{\text {a }}$ Região fixou, por meio da Resolução n. ${ }^{\circ}$ 101, de 15 de agosto de 2014, que "Os pedidos de cooperação jurídica passiva em matéria penal, tanto por meio de carta rogatória quanto por meio de cooperação direta com intervenção judicial, encaminhados à Justiça Federal da $4^{\text {a }}$ Região serão processados, no âmbito da respectiva Seção Judiciária, pelos juízos da $7^{\text {a }}$ Vara Federal de Porto Alegre, da $7^{\text {a }}$ Vara Federal de Florianópolis e da $13^{\text {a }}$ Vara Federal de Curitiba"40. Isso permite que a dinâmica do fluxo de comunicação seja ágil e apta a executar as medidas solicitadas. No exemplo citado, trata-se de medida dependente da chancela judicial, o que nem sempre ocorre, já que existe a possibilidade de pedidos para o cumprimento de medidas administrativas que poderiam ficar a cargo do Ministério Público ou das Polícias, diretamente.

No caso do MERCOSUL, com o processo de integração para a coordenação de ações na área criminal, essa dificuldade pode ser minimizada. A esse respeito, o Sistema de

38 Em BONDT, Wendy, RYCKMAN, Charlotte e VERMEULEN, Gert - «Horizontalisation and decentralisation...». In: VERMEULEN, G.; BONDT, W.; RYCKMAN, C.(eds.) Rethinking international cooperation in criminal ..., p. 185.

39 AMICIS, Gaetano De - «La cooperacione orizzontale». In: KOSTORIS, Roberto E. Manuale di procedura penale europea. Milano: Giuffrè Editore, 2017, p. 271.

40 Disponível em <https://www2.trf4.jus.br/trf4/diario/visualiza_documento_adm.php?orgao=1\&id_materia= 21511 \&reload=false $>$ acesso em 28 jan 2021. 
Intercâmbio de Informação de Segurança do MERCOSUL (SISME), criado pela MERCOSUL/CMC/DEC N. ${ }^{\circ}$ 36/04 e atualizado conforme CMC/DEC N. ${ }^{\circ}$ 17/17, considera "que para enfrentar as atividades do crime transnacional organizado é essencial contar com um ágil e oportuno intercâmbio de informação" (preâmbulo) ${ }^{41}$, e que o SISME se constitui em ferramenta ao intercâmbio de dados sobre bens (apreensão de veículos e armas), pessoas (pedidos de prisão, proibições e autorizações de entrada e saída de pessoas nacionais ou estrangeiras, etc.), podendo expandir-se para dados vinculados ao crime organizado transnacional, informações sobre embarcações, etc. ${ }^{42}$ O SISME pode ser alimentado com dados relacionados à cooperação judicial internacional, estabelecendo as contrapartes em cada um dos países, de acordo com a necessidade pontual dos pedidos de cooperação. Assim, essa ferramenta já pode solucionar, em grande parte, a dificuldade identificada, criando esquemas organizacionais das partes envolvidas na cooperação, facilitando o encaminhamento direto dos pedidos.

O segundo entrave diz respeito à linguagem e tradução dos documentos e pedidos. Ora, no contexto regional esse é um entrave de pouca repercussão pois, com a exceção do Brasil, os demais países adotam a língua espanhola (com variações locais). Para sanar essa dificuldade, o auxílio das Autoridades Centrais pode ser fundamental, embora o corpo especializado dos órgãos, como mencionado anteriormente, deveria ser composto por equipe que tenha aptidão nos dois idiomas oficiais do MERCOSUL, ou ainda, investimento na capacitação específica nessa área.

O benefício de ter apenas dois idiomas oficiais correntes, e com isso operacionalizar os pedidos a eles restritos, não é, a priori, compartilhado pela União Europeia, composta por 28 Estados Membros com 24 línguas oficiais diferentes ${ }^{43}$. Assim, o intercâmbio acabou sendo concentrado, na prática, na língua inglesa, padronizando a forma de se comunicar ${ }^{44}$.

Outra proposta que pode auxiliar na redução de ruídos de comunicação entre os países parte do MERCOSUL é a tradução, por meio de um corpo técnico especializado, das legislações pertinentes (Códigos de Processo Penal, Códigos Penais, etc.). Essa medida, para o futuro, também contribui ao intercâmbio técnico, integração e harmonização das legislações, aspirações contidas no Tratado de Assunção. De fato, o problema da tradução não se revela impeditivo, mas faz parte do processo de integração regional. O caminho natural

41 Disponível em <https://www.mercosur.int/documentos-y-normativa/normativa/> acesso em 28 jan 2021.

42 Anexo - Sistema de Intercâmbio de Informação de Segurança do MERCOSUL. GMC/RES N. ${ }^{\circ}$ 26/01 - ART. 4. ${ }^{\circ}$, com atualização de 22/11/2018.

43 Disponivel em <https://publications.europa.eu/pt/publication-detail/-/publication/715cfcc8-fa70-11e7-b8f5olaa75ed71a1> acesso em 28/01/2021.

44 Em BONDT, Wendy, RYCKMAN, Charlotte e VERMEULEN, Gert - «Horizontalisation and decentralisation...». In: VERMEULEN, G.; BONDT, W.; RYCKMAN, C.(eds.) Rethinking international cooperation in criminal ..., p. 189. 
Cooperação judicial em matéria criminal no mercosul: reconhecimento mútuo e modelo horizontal de cooperação NEREU JOSÉ GIACOMOLLI, CAÍQUE RIBEIRO GALÍCIA

GALILEU - e-ISSN 2184-1845 - Volume XXI - Issue Fascículo 2 - $1^{\text {st }}$ July Julho - 31 st $^{\text {t }}$ December Dezembro $2020 \cdot$ pp. $77-94$

com a maior integração nesse tema será a compreensão mais ou menos igualitária dos dois idiomas, mas até lá, as Autoridades Centrais podem fornecer o suporte técnico necessário para este desiderato.

Por último, os entraves técnicos (recursos humanos, treinamento e equipamentos) correspondem a uma dificuldade que está afeita a maior parte dos setores burocráticos na realidade regional. Tais dificuldades podem se dar no campo da disponibilidade de recursos humanos, na qualificação desses recursos (especialização e treinamento) e na limitação técnica propriamente dita (recursos informáticos, telefônicos, internet, etc.).

Importante destacar que, como já afirmado, o papel das Autoridades Centrais não é descartado no processo de cooperação internacional descentralizada. Aliás, exatamente nos entraves técnicos é que ela tem um papel fundamental para auxiliar o desenvolvimento das atividades e de tomadas de decisões, que devem permanecer com as autoridades descentralizadas.

Por razões óbvias, as questões técnicas à implementação da cooperação descentralizada deverá ser foco de investimento por parte dos países parte do MERCOSUL nas várias dimensões citadas. Mas isso é um desdobramento usual de qualquer aparelhamento burocrático, que no caso da cooperação internacional em matéria criminal, ainda poderá ter o suporte das Autoridades Centrais, que devem monitorar os pedidos, levantar dados estatísticos para auxiliar todo o processo.

No geral, o quadro proposto é favorável à implementação de uma cooperação internacional em matéria criminal na forma descentralizada, fundada no princípio do mútuo reconhecimento. Contudo, não se pode ignorar que existem alguns pedidos cooperacionais que demandam outro tratamento, constituindo, neste aspecto, exceções à regra da descentralização. Uma dessas exceções, pode ser a transferência de pessoas condenadas. Afinal, existe uma carga muito maior de responsabilidade no acolhimento ou não de pedidos de cooperação neste aspecto. Sem embargo, reconhecendo a possibilidade de exceções à regra da descentralização, a cooperação internacional em matéria criminal, de forma horizontal (diretamente entre autoridades nacionais), é a forma mais adequada e eficiente em alguns aspectos. No caso da busca e coleta de elementos probatórios, se constitui em mecanismo adequado ao desenvolvimento de atos cooperacionais.

É certo que a cooperação internacional ainda demanda muitas reflexões para sua efetiva expansão como um mecanismo seguro e confiável na persecução penal no âmbito do MERCOSUL. Em razão da dinâmica da criminalidade transnacional, requer-se esforços conjuntos e compartilhados para, superando a ideia de uma concepção hermética de Estado, viabilizar a solidariedade internacional na afirmação do Estado de Direito e na tutela dos direitos fundamentais. 


\section{CONSIDERAÇÕES FINAIS}

O presente estudo buscou apresentar um aparto geral sobre a cooperação jurídica internacional em matéria criminal no contexto do MERCOSUL. Por se inserir na dinâmica da criminalidade transnacional, naturalmente deve se mostrar como tema com muitas variáveis - além da velocidade da contemporaneidade - e com menor "estabilidade" do que os temas clássicos do Direito Criminal. Conscientes da limitação da abordagem e do recorte apresentado, buscou-se apresentar algumas reflexões sobre a realidade do MERCOSUL a partir de uma leitura do reconhecimento mútuo e da harmonização da legislação. Essa constatação é importante na medida em que evidenciam-se as características regionais próprias em contraponto ao modelo europeu. De fato, o processo de integração do MERCOSUL é bastante diferente do que acontece no espaço europeu, mas a realidade de permeabilidade das fronteiras, somada à expansão da criminalidade transnacional, impõe medidas compartilhadas pelos países. A persecução penal necessita se equilibrar nessa tênue linha entre integração de mercados e intersecção de jurisdições para dar uma resposta que seja condizente com os parâmetros democráticos e de respeito dos direitos humanos.

Nessa perspectiva é viável a harmonização da legislação criminal dos países a partir do respeito ao eixo comum: Convenção Americana dos Direitos Humanos (CADH). Naturalmente, há diversos fatores complicadores, especialmente relacionados com uma concepção clássica de Estado nação, fechado, já não mais adequado à realidade contemporânea. A esse respeito, preconiza-se a desnecessidade ou a redução ao mínimo possível das hipóteses de limitação da cooperação judicial internacional com base na ideia de dupla incriminação, apenas. Isso porque os sistemas de justiça do MERCOSUL já tutelam (com ressaltas específicas e alguns critérios diferentes) a grande maioria dos bens jurídicos relacionados com a criminalidade transnacional. Por isso, se faz mister reduzir ao máximo as possibilidades controle político das hipóteses de denegação de pedidos de cooperação, não raras vezes tranvestidas de "técnicos", mas que, na verdade, representam "tecnicismos" acríticos.

Assim, defende-se a viabilização de alternativas para que a cooperação se dê no espaço do MERCOSUL de forma horizontal e descentralizada, sem desprezar o relevante papel das Autoridades Centrais, mormente no que pertine à facilitação do processamento dos pedidos. Faz-se mister, porém, buscar a racionalização da cooperação judicial como instrumento da persecutio criminis, mas também da proteção dos direitos fundamentais, para além do controle político. São reflexões que estão abertas ao diálogo crítico-construtivo, representando ideias desenvolvidas a partir de pesquisa científica consciente da finitude 
e limitação metodologia, temporal e prática. E por isso, pretende trazer o tema à tona para discussão e contribuição de novas pautas de pesquisa que possam surgir.

\section{REFERÊNCIAS}

AMICIS, Gaetano De - «La cooperacione orizzontale». In: KOSTORIS, Roberto E. Manuale di procedura penale europea. Milano: Giuffrè Editore, 2017.

APRILE, Ercole - Diritto Processuale Penale Europeo e Internazionale. Padova: CEDAM, 2007.

BECHARA, Fábio Ramazzini - Cooperação jurídica internacional em matéria penal. Eficácia da prova produzida no exterior. São Paulo: Saraiva, 2011.

BECK, Ulrich - A Europa alemã de Maquiavel a Merkievel: estratégias de poder na crise do euro. Lisboa: Edições 70, 2013.

BONDT, Wendy De - «Double criminality in international cooperation in criminal matters». In: VERMEULEN, G.; BONDT, W.; RYCKMAN, C.(eds.) Rethinking international cooperation in criminal matters in the EU. Antwerpen: Maklu, 2012.

CERVINI, Raúl e TAVARES, Juarez -Princípios de cooperação judicial penal internacional no Protocolo do Mercosul. São Paulo: Revista dos Tribunais, 2000.

GIDDENS, Anthony - Mundo em descontrole: o que a globalização está fazendo de nós. Rio de Janeiro: Record, 2011.

MARTINEZ, Rosa Ana Morán - «La cooperación judicial internacional en el siglo XXI». In: MINISTÉRIO PÚBLICO FEDERAL. Temas de cooperação internacional. Brasília: MPF, 2016.

MAZZUOLI, Valerio de Oliveira - Os sistemas regionais de proteção dos direitos humanos. Uma análise comparativa dos sistemas interamericano, europeu e africano. São Paulo: Revista dos Tribunais, 2011.

MOREDA, Nicolás Alonso - Cooperación judicial em matéria penal em la Unión Europea: la "euro-ordem", instrumento privilegiado de cooperación. Pamplona: Thomson Reuters, 2016.

REZEK, Francisco - Direito internacional público. Curso elementar. São Paulo: Saraiva, 2011.

RUSSOWSKY, Iris Saraiva - O mandado de detenção na União Européia: um modelo para o Mercosul. Porto Alegre: Verbo Jurídico, 2012.

SAADI, Ricardo A. e BEZERRA, Camila C. - «A autoridade central no exercício da cooperação jurídica internacional». In: DEPARTAMENTO DE RECUPERAÇÃO DE ATIVOS E COOPERAÇÃO JURÍDICA INTERNACIONAL. Manual de Cooperação jurídica internacional e recuperação de ativos: cooperação em matéria penal. Brasília: Ministério da Justiça, 2012.

SPENCER, John R. - «Mutuo Riconoscimento, armonizzazione e tradizionali modelli intergovernativi». In: KOSTORIS, Roberto E. Manuale di procedura penale europea. Milano: Giuffrè Editore, 2017.

VALENTE, Manuel Monteiro Guedes - Do Mandado de Detenção Europeu. Coimbra: Almedina, 2006.

WEYEMBERGH, Anne - «La cooperazione giudiziaria e di polizia». In: KOSTORIS, Roberto E. Manuale di procedura penale europea. Milano: Giuffrè Editore, 2017.

ZAKARIA, Fareed - The post-american world. New York: W. W. Norton \& Company, 2008. 